\title{
In vitro effect of lysophosphatidic acid on proliferation, invasion and migration of human ovarian cancer cells
}

\author{
Qingfu Wang ${ }^{1 *}$, Lixin $\mathrm{Zhu}^{2}$, Aiping Qin ${ }^{2}$, Tiefeng Chen ${ }^{1}$, Jinpen $\mathrm{Li}^{1}$, Beitai $\mathrm{Wu}^{1}$, \\ Yu Xiao ${ }^{1}$, Zongan Lai ${ }^{1}$, Weixiong Xie ${ }^{1}$ \\ ${ }^{1}$ People's Hospital of Dianbai of Maoming City, Maoming 525400, ${ }^{2}$ Southern Medical University, Guangzhou 510515, China \\ *For correspondence: Email: docwangqingfu@126.com
}

\begin{abstract}
Purpose: To evaluate the effect of lysophosphatidic acid (LPA) on the proliferation, invasion and migration ability of $3 A O$, SKOV3 and CAOV3 human ovarian cancer cell lines.

Methods: SKOV3, $3 A O$ and CAOV3 cell lines were respectively treated with LPA. Changes in the proliferation rate of these cell lines were observed after LPA treatment. The cell lines that were not treated with LPA served as control group. Boyden chamber was used to assess cell invasion and migration capability. The expression levels of relevant cytokines related to cell migration in the supernatant of CAOV3 cell line were determined using ELISA following LPA stimulation.

Results: The cell proliferation rate of human ovarian cancer cell lines was significantly accelerated after in vitro LPA treatment in a concentration-dependent fashion. Boyden chamber assay data indicate that invasion indices in $3 A O$ and CAOV3 cell lines were significantly higher than those in untreated control cell lines $(p<0.05)$. However, no statistical significance was noted between $3 A O$ and CAOV3 cell lines $(p<0.05)$. The expression levels of relevant cytokines in the CAOV3 cell line were significantly upregulated after $L P A$ treatment $(p<0.05)$.

Conclusion: LPA intervention in vitro accelerates cell proliferation rate and also significantly upregulates the expression levels of multiple cytokines related to cell migration in human ovarian cancer cell lines, suggesting that LPA plays a significant role in the invasion and migration of SKOV3, 3AO and CAOV3 cell lines.
\end{abstract}

Keywords: Ovarian carcinoma, Tumor infiltration, Lysophosphatidic acid, Cell migration, Cytokines

\begin{abstract}
This is an Open Access article that uses a funding model which does not charge readers or their institutions for access and distributed under the terms of the Creative Commons Attribution License (http://creativecommons.org/licenses/by/4.0) and the Budapest Open Access Initiative (http://www.budapestopenaccessinitiative.org/read), which permit unrestricted use, distribution, and reproduction in any medium, provided the original work is properly credited.
\end{abstract}

Tropical Journal of Pharmaceutical Research is indexed by Science Citation Index (SciSearch), Scopus, International Pharmaceutical Abstract, Chemical Abstracts, Embase, Index Copernicus, EBSCO, African Index Medicus, JournalSeek, Journal Citation Reports/Science Edition, Directory of Open Access Journals (DOAJ), African Journal Online, Bioline International, Open-J-Gate and Pharmacy Abstracts

\section{INTRODUCTION}

Lysophosphatidic acid (LPA) is a bioactive lipid mediator involved in tissue repair and wound healing. It mediates diverse functional effects in fibroblasts, including proliferation, migration and contraction, but less is known about its ability to evoke paracrine signaling to other cell types. In recent years, LPA and its receptor signaling pathways have been shown to be implicated in the incidence, invasion and migration processes of malignant tumors [1-6].

Ovarian cancer is a highly metastatic disease which is characterized by ascites formation and adhesion, invasion, and metastasis. Levels of 
LPA are significantly increased in the plasma of ovarian carcinoma patients, indicating that LPA can promote the incidence of early events in ovarian carcinoma dissemination. LPA is capable of playing a role via its receptors. LPA receptors belong to the endothelial differentiation gene (Edg) family, which consists of 4 categories. In particular, LPA1/Edg-2, LPA2/Edg-4 and LPA3/Edg-7 are frequently investigated.

Recent studies [1,3] have demonstrated that $G$ protein-coupled receptor 23 (GPR23)/p2y9/LPA4 is lowly expressed in the ovarian tissues of most healthy subjects. However, Edg-4 and Edg-7 are highly expressed in human ovarian cancer cell lines. LPA is able of accelerating DNA synthesis after binding with Edg-4 and Edg-7. LPA has been identified to regulate the proliferation, migration and adhesion of cancer cells, the release and activation of matrix metalloproteinase (MMP) and the secretion of angiogenesis factors [7-9], indicating that LPA plays a pivotal role in the invasion and metastasis processes of malignant tumor cells.

In this study, human ovarian cancer cell lines including $3 \mathrm{AO}, \mathrm{CAOV} 3$ and SKOV3 were selected and treated with different concentrations of LPA. Subsequently, the growth, proliferation, invasion and metastasis ability of the ovarian cancer cells were evaluated after LPA treatment. The expression levels of multiple cytokines related to cellular invasion and migration were also quantitatively measured.

\section{EXPERIMENTAL}

\section{MTT assay}

The effect of LPA upon the growth and proliferation of ovarian cancer cell lines was assessed by MTT assay. The ovarian cancer cell lines $3 \mathrm{AO}, \mathrm{SKOV} 3$ and CAOV3 were cultured in RPMI1640 complete culture solution containing 10 $\%$ fetal bovine serum at $37{ }^{\circ} \mathrm{C}$ and $5 \% \mathrm{CO}_{2}$. The ovarian cancer cell lines were inoculated for $24 \mathrm{~h}$ and serum-free culture solution was supplemented overnight. The obtained cell lines were inoculated in a 96-well plate at a cell density of $5 \times 10^{3} /$ well, cultured for $24 \mathrm{~h}$ using conventional method and co-cultured with different concentrations of $\operatorname{LPA}(0.2,2,10$ and $20 \mu \mathrm{mol} / \mathrm{L})$.

The culture solution was abandoned at 2, 4, 6, 16 and $24 \mathrm{~h}$ after LPA supplement, a portion of 20 $\mathrm{mL}$ MTT solution at a concentration of $5 \mu \mathrm{g} / \mu \mathrm{L}$ was added in each well, continuously cultured for $4 \mathrm{~h}$, and $150 \mathrm{~mL}$ DMSO was supplemented in each well. The absorbance value of each well was measured at a wavelength of 490 and $620 \mathrm{~nm}$.
The cell growth curve was drawn. The cell proliferation rate $=$ (Absorbance value LPA groupabsorbance value control group)/absorbance value control group $\times 100 \%$. Three replicates were set for each concentration in each well. In the control group, LPA was substituted with the PBS.

\section{Boyden chamber assay}

The ovarian cancer cell lines $3 \mathrm{AO}$ and CAOV3 were cultured in RPMI1640 complete culture solution containing $10 \%$ fetal bovine serum. In the LPA group, 5 and $20 \mu \mathrm{mol} / \mathrm{L}$ of LPA was added and PBS was used in the control group for $16 \mathrm{~h}$. The obtained cells in logarithmic phase were digested in $0.25 \%$ pancreatin and a portion of 80 $\mu \mathrm{L}$ suspension containing $2 \times 10^{6}$ of cells was prepared. Artificial matrix gel matrige1 (BD corporation, U.S.) was smeared on polycarbonate millipore filter (Waltman, U.S.) approximately 150 $\mu \mathrm{g}$ for each well and maintained at $37^{\circ} \mathrm{C}$ for $3 \mathrm{~h}$, air dried at room temperature overnight.

A portion of $20 \mu \mathrm{L}$ serum-free solution was added in the lower Boyden chamber and pretreated cell suspension was added in these upper Boyden chamber. The obtained cells were cultured at 37 ${ }^{\circ} \mathrm{C}$ and $5 \% \mathrm{CO}_{2}$ for $18 \mathrm{~h}$, fixed in $70 \%$ methanol for $45 \mathrm{~min}$, stained in hematoxylin for 1 - $2 \mathrm{~min}$, washed triple times using distilled water, transferred on to a slide, sealed with a cover slip and observed under high-power light microscope. Three replicates were set for each concentration in each well. In the control group, LPA was substituted with PBS.

\section{Cytokine detection after LPA treatment}

The CAOV3 cell line was cultured in serum-free solution for $12 \mathrm{~h}$ and treated with different concentrations of LPA $(5,20$ and $40 \mu \mathrm{mol} / \mathrm{L})$ for $16 \mathrm{~h}$, and LPA was replaced by PBS in the control group. The treated cells in logarithmic growth phase were digested using $0.25 \%$ pancreatin containing $10 \%$ fetal bovine serum, transferred into the centrifuge tube and added by $100 \mu \mathrm{L}$ culture solution. The cell suspension at a density of $2 \times 10^{6} / \mathrm{mL}$ was prepared using $0.9 \%$ cell suspension and the supernatant was preserved at $-80^{\circ} \mathrm{C}$.

After LPA treatment at a concentration of $(0,5,20$ and $40 \mu \mathrm{L} / \mathrm{L}$ ), CXCL12 (C-X-C motif ligand12), Ecadherin, vascular endothelial growth factor (VEGF), vascular endothelial growth factor receptor (VEGFR), epidermal growth factor (EGF), epidermal growth factor receptor (EGFR) were quantitatively measured using ELISA ( $R$ \& D Systems Inc.). The experimental procedures were performed strictly according to the 
manufacturer's instructions. Three replicates were set for each concentration in each well. In the control group, LPA was substituted with PBS.

\section{Statistical analysis}

SPSS19.0 statistical software was used for statistical analysis and the data are expressed as mean \pm standard deviation (SD). Replicate data were statistically analyzed by ANOVA. Group comparison was performed by LSD test. $P<0.05$ was considered statistically significant.

\section{RESULTS}

\section{Effect of LPA treatment upon ovarian cancer cell growth and proliferation}

The cell lines were treated with different concentrations of LPA, the absorbance values in the LPA group were significantly higher compared with those in the control group. At 10 $\mu \mathrm{mol} / \mathrm{L} \mathrm{LPA}$ treatment for $16 \mathrm{~h}$, the proliferation rate of $3 \mathrm{AO}, \mathrm{SKOV} 3$ and CAOV3 cell lines was significantly enhanced compared with that in the control group, as illustrated in Figure 1.

\section{Effect of LPA upon ovarian cancer cell invasion}

The outcome of cell invasion did not significantly differ between the $3 A O$ and $\mathrm{CAOV} 3$ cell lines treated with PBS, 5 and $20 \mu \mathrm{mol} / \mathrm{L}$ LPA $\left(x^{2}=\right.$ $3.648, p=0.052 ; x^{2}=3.283, p=0.056 ; x^{2}=3.431$, $p=0.054)$. In the $3 A O$ and CAOV3 cell lines, the invasion ability was significantly increased after 5 and $20 \mu \mathrm{mol} / \mathrm{L}$ treatment $\left(x^{2}=4.355, p=0.029 ; x^{2}\right.$ $=4.170, p=0.012)$. Statistical significance was also observed between the 5 and $20 \mu \mathrm{mol} / \mathrm{L}$ intervention groups $\left(x^{2}=4.288, p=0.037\right)$, as illustrated in Figure 2 and Table 1 . The invasion ability was positively correlated with increasing LPA concentration.

Table 1: Effect of different concentrations of LPA on the invasion capability of $3 \mathrm{AO}$ and $\mathrm{CAOV} 3$ cell lines

\begin{tabular}{lcc}
\hline LPA concentration & \multicolumn{2}{c}{ Invasion capability } \\
\cline { 2 - 3 }$(\boldsymbol{\mu m o l} / \mathrm{L})$ & $\mathbf{3 A O}$ & CAOV3 \\
\hline Blank control & $23.5 \pm 1.1$ & $22.8 \pm 1.2$ \\
$5 \mu \mathrm{mol} / \mathrm{L}$ LPA & $25.7 \pm 1.3^{\prime \prime}$ & $24.8 \pm 0.7^{\prime \prime}$ \\
$20 \mu \mathrm{mol} / \mathrm{L}$ LPA & $30.4 \pm 1.7^{\text {\# }}$ & $29.2 \pm 1.1^{\text {\#\# }}$ \\
\hline
\end{tabular}

Note: ${ }^{*} X^{2}=4.355, p=0.029$ compared with the blank control group; $\# x^{2}=4.170, p=0.043$ compared with the blank control group; ${ }^{\wedge} X^{2}=4.221, p=0.037$ compared with the $5 \mu \mathrm{mol} / \mathrm{L}$ LPA group

\section{Effect of LPA on expression levels of multiple cytokines}

The expression levels of CXCL12, E-cadherin, VEGF, VEGFR, EGF and EGFR in the CAOV3 cell supernatant after 5,20 and $40 \mu \mathrm{mol} / \mathrm{L}$ treatment with LPA are shown in Table 2. No
A

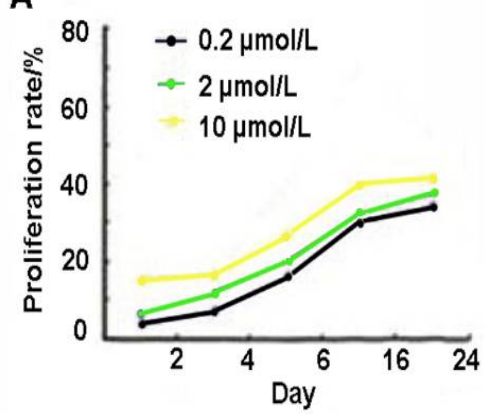

B

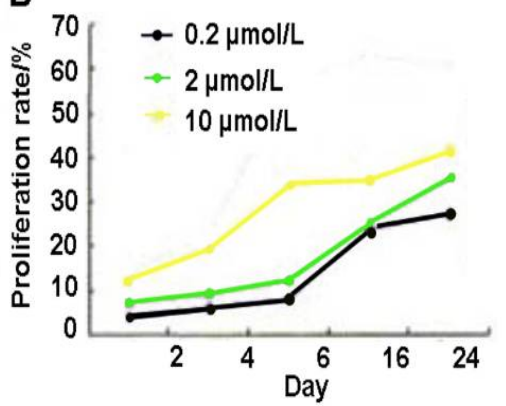

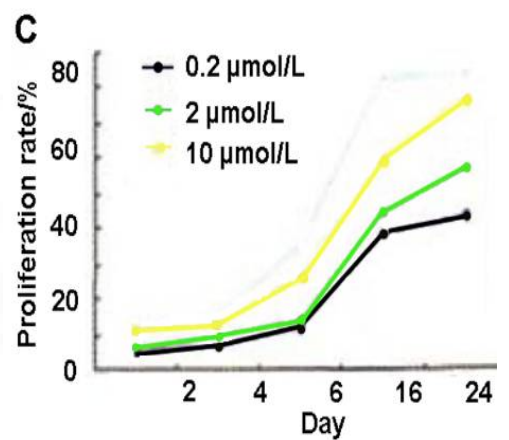

Figure 1: Effect of different concentrations of LPA on the proliferation rates of $3 A O(A)$, SKOV3 (B) and CAOV3 (C) cell lines
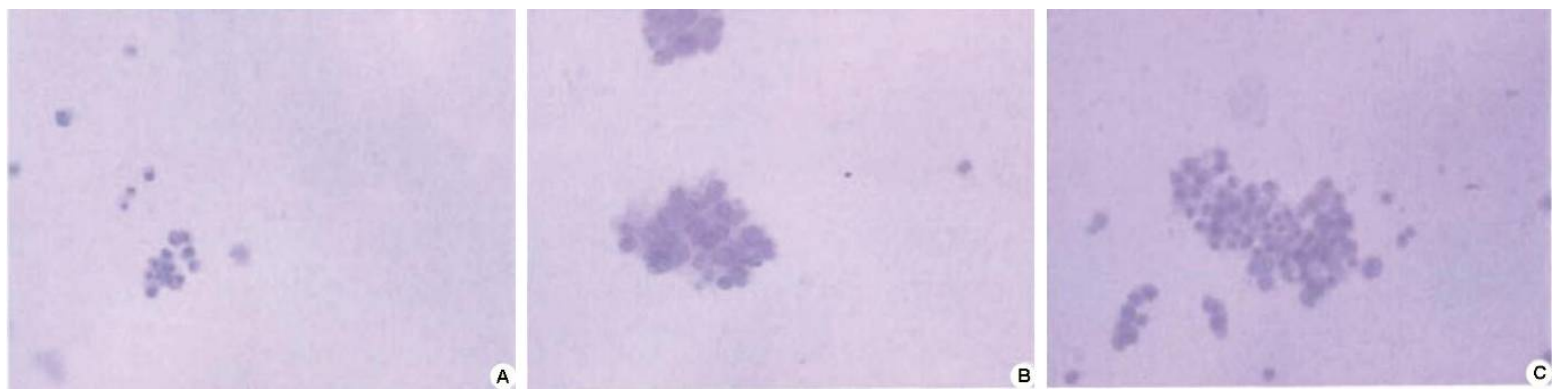

Figure 2: Morphological effect of LPA on the invasion capability of CAOV3 cells by Boyden chamber assay ( $\times$ 200 ) in the control (A), $5 \mu \mathrm{mol} / \mathrm{L}(B)$ and $20 \mu \mathrm{mol} / \mathrm{L}(\mathrm{C})$ of LPA 
Table 2: Effect of different concentrations of LPA on the expression levels of multiple cytokines

\begin{tabular}{|c|c|c|c|c|c|c|}
\hline Parameter & $\begin{array}{c}0 \\
\text { LPA }\end{array}$ & $5 \mu \mathrm{mol} / \mathrm{L}$ LPA & $20 \mu \mathrm{mol} / \mathrm{L}$ LPA & $40 \mu \mathrm{mol} / \mathrm{L}$ LPA & $\begin{array}{c}F- \\
\text { value }\end{array}$ & $\begin{array}{c}P- \\
\text { value }\end{array}$ \\
\hline CXCL12 ( $\mathrm{mmol} / \mathrm{L})$ & $2.21 \pm 1.01$ & $1.65 \pm 0.32$ & $1.51 \pm 0.05$ & $1.48 \pm 0.14$ & 1.733 & 0.055 \\
\hline VEGF (ng / mL) & $1.12 \pm 0.05$ & $1.15 \pm 0.02$ & $1.15 \pm 0.05$ & $1.18 \pm 0.03$ & 5.022 & 0.002 \\
\hline $\operatorname{VEGFR}(\mathrm{nmol} / \mathrm{L})$ & $70.25 \pm 4.23$ & $100.02 \pm 0.03$ & $100.04 \pm 0.03$ & $100.05 \pm 0.01$ & 5.002 & 0.011 \\
\hline EGF (pg/mL) & $39.55 \pm 4.42$ & $41.25 \pm 1.25$ & $37.20 \pm 0.00$ & $39.59 \pm 0.02$ & 5.688 & 0.005 \\
\hline EGFR (ng / mL) & $1.82 \pm 0.24$ & $1.55 \pm 0.24$ & $1.48 \pm 0.45$ & $1.51 \pm 0.04$ & 1.755 & 0.188 \\
\hline E-cadherin (pmol / L) & $13.33 \pm 1.21$ & $12.95 \pm 4.21$ & $19.88 \pm 0.48$ & $23.21 \pm 9.21$ & 4.002 & 0.015 \\
\hline
\end{tabular}

statistical significance was observed of the CXCL12 expression level between the control and the LPA treatment groups $(F=1.738, p=$ 0.052). The expression level of E-cadherin significantly differed between the control and LPA treatment groups $(F=4.073, p=0.021)$. Statistical significance was observed in Ecadherin level among different concentrations of the LPA groups $(p=0.004)$.

The expression level of E-cadherin was significantly up-regulated along with increasing concentration of LPA. In the LPA intervention group, the expression level of VEGF ranged from 1.08 to $1.19 \mathrm{ng} / \mathrm{mL}$ with a median value of 1.14 $\mathrm{ng} / \mathrm{mL}$, significantly higher compared with that in the control group $(F=5.032, p=0.002)$. The expression levels of VEGF did not significantly differ among different LPA concentration groups. Nevertheless, the expression level increased along with elevation of LPA concentration. The expression levels of VEGFR in the different LPA concentration groups were all significantly upregulated compared with that in the control group $(F=5.000, p=0.010)$, whereas no statistical significance was observed among different LPA concentration groups.

The expression levels of EGF significantly differed between the control and LPA treatment groups $(F=5.678, p=0.006)$, whereas no statistical significance was observed among different LPA concentration groups (all $p>0.05$ ). EGF expression significantly differed between the 5 and $20 \mu \mathrm{mol} / \mathrm{L}$ treatment groups $(p=0.001)$. No statistical significance was observed between the 5 and $40 \mu \mathrm{mol} / \mathrm{L}$ groups $(p=0.055)$ in terms of the EGF expression level.

Statistical significance was observed between the 20 and $40 \mu \mathrm{mo} 1 / \mathrm{L}$ LPA groups $(p=0.000)$, suggesting that the expression of EGF showed a dose-dependent fashion. No statistical significance was observed in the EGFR expression levels between the LPA treatment and control groups or among different LPA concentration groups $(F=1.754, p=0.189)$.

\section{DISCUSSION}

Previous studies have demonstrated that LPA receptor is expressed in the human ovarian cancer cell lines 3AO, SKOV3 and CAOV3 [9]. LPA possesses multiple biological functions through LPA receptors located on the cell membrane. LPA has been shown to play a vital role in the invasion and migration of malignant tumor cells. The findings in this study further demonstrate that LPA administration is able to enhance the proliferation of ovarian cancer cells, which is consistent with previous investigations [10].

Boyden chamber experiment revealed that the invasion capability of $3 \mathrm{AO}$ and CAOV 3 cell lines was significantly increased after LPA treatment, which was significantly higher compared with that in the control group. In addition, the invasion ability of ovarian cancer cells was positively correlated with increasing concentration of LPA administration. However, no statistical significance was observed in the cell invasion between $3 A O$ and CAOV 3 cell lines.

The results of this investigation indicate that LPA is capable of binding with tumor cell surface receptors to participate in the growth, proliferation and migration of malignant tumor cells. The supernatant solution of the ovarian cancer cell suspension was collected and demonstrated that LPA can stimulate the growth of CAOV3 cell line and significantly up-regulate the expression level of CXCL12 cytokines. These findings collectively suggest that CAOV 3 cell line is able to secrete a certain quantity of CXCL12, which is capable of binding with CXCR4 to induce the formation of actin-related pseudopod and regulate the directional migration, invasion and angiogenesis of tumor cells. CXCL12 is highly expressed in the ascites of ovarian cancer patients, suggesting that CXCLI2/CXCR4 probably plays a role in the metastasis of ovarian cancer. Statistical analysis revealed statistical significance in the E-cadherin expression level in the supernatant after corresponding LPA treatment. The expression level of E-cadherin was significantly up-regulated along with increasing concentration of LPA administration, indicating that E-cadherin 
expression is positively correlated with LPA concentration, thereby affecting cancer cell formation. Moreover, LPA treatment can affect the adaptability of tumor cells towards external environment, which potentially increases the resistance ability of cancer cells towards chemotherapeutic agents.

Similarly, the expression level of VEGF in the supernatant of ovarian cancer cell line was also positively correlated with increasing concentration of LPA treatment. VEGF is a pivotal signaling protein involved in both vasculogenesis, and angiogenesis. The activity of VEGF is restricted mainly to the vascular endothelial cells, although it exerts effects upon a limited quantity of other cell types, such as stimulation monocyte/macrophage migration. In vitro experiment demonstrates that VEGF can stimulate endothelial cell mitogenesis and cell migration. VEGF also enhances microvascular permeability and is occasionally referred as vascular permeability factor. The increase in VEGF concentration can up-regulate the expression level of VEGFR, which is considered a vital mechanism underlying the effect of VEGF on the promotion of angiogenesis of tumor tissues [11].

The expression level of VEGFR in the LPA treatment group was significantly up-regulated compared with that in the control group, whereas no statistical significance was observed among different LPA concentration groups. The CAOV3 cancer cells can secrete VEGFR via autocrine or paracrine pathway, which migrate into ascites or extracellular space. The interaction between VEGF and VEGFR is capable of provoking the migration of ovarian cancer cells.

Similarly, the expression level of EGF in the LPA treatment group was significantly up-regulated compared with that in the control group. In addition, the expression level of EGF was increasingly up-regulated along with increasing concentration of LPA, which peaked at $20 \mu \mathrm{mol} / \mathrm{L}$ and subsequently began to decline. The expression level of EGF after $20 \mu \mathrm{mol} / \mathrm{L}$ LPA treatment was significantly higher compared with that following $40 \mu \mathrm{mol} / \mathrm{L}$ LPA treatment. Although the expression level of EGFR is regulated by the LPA in a concentration-dependent manner, no statistical significance was detected among different LPA concentration groups, which is consistent with our previous findings that the expression level of EGFR is low in the chylous ascites of ovarian cancer patients, suggesting that LPA exerts no significant effect upon the production of EGFR by ovarian cancer cells.
The experimental results in this investigation revealed that LPA exerts a nonsynchronous effect upon the production of EGF and EGFR. Previous investigations have demonstrated that CXCLI2 can stimulate the growth and proliferation of ovarian cancer cells through mediating the EGFR [12]. Though the content of soluble EGFR is relatively low, the biological role of EGFR should be emphasized. The role of EGF-EGFR interaction in the invasion and metastasis of ovarian cancer remains to be elucidated.

In this investigation, LPA exerts different effects on CXCL12, VEGF and their receptors, whereas it does not affect the level of CXCLI2 secreted by ovarian cancer cells. However, LPA exerts a significant effect upon VEGF and VEGFR, indicate that blockage of CXCR4/CXCL12 biological axis can inhibit tumor growth and suppress the role of VEGF in vascularization, which is consistent with previous reports [13,14]. The findings in this investigation may provide alternative evidence for the clinical treatment of ovarian cancer.

\section{CONCLUSION}

LPA treatment in vitro enhances cell proliferation rate and significantly up-regulates the expression levels of multiple cytokines associated with cell migration in human ovarian cancer cell lines, indicating that LPA plays a significant role in the invasion and migration of SKOV3, 3AO and CAOV3 cells.

\section{DECLARATIONS}

\section{Conflict of Interest}

There are no competing interests with regard to this work.

\section{Contribution of authors}

We declare that this work was done by the authors named in this article and all liabilities pertaining to claims relating to the content of this article will be borne by the authors. Qingfu Wang, Lixin Zhu and Aiping Qin were responsible for research design and manuscript draft. Tiefeng Chen and Jinpen Li were in charge of study design. Beitai $\mathrm{Wu}$ was responsible for data analysis. Yu Xiao, Zongan Lai and Weixiong Xie were in charge of proofreading. All authors have reviewed the final version manuscript. 


\section{REFERENCES}

1. Landen CN (Jr), Birrer MJ, Sood AK. Early events in the pathogenesis of ovarian cancer epithelial ovarian cancer. J Clin Oncol 2008; 26: 995-1005.

2. Eder AM, Sasagawa T, Mao M, Aoki J, Mills GB. Constitutive and lysophosphatidic acid (LPA)-induced LPA production: role of phospholipase $D$ and phospholipase A2. Clin Cancer Res 2000; 6: 2482-2491.

3. Ren J, Xiao YJ, Singh LS, Zhao X, Zhao Z, Feng L, Rose $T M$, Prestwich GD, XU Y. Lysophosphatidic acid is constitutively produced by human peritoneal mesothelial cells and enhances adhesion, migration, and invasion of ovarian cancer cells. Cancer Res 2006; 66: 3006-3014.

4. Bian D, Su S, Mahanivong C, Cheng RK, Han Q, Pan ZK, Sun $P$, Huang $S$. Lysophosphatidic acid stimulates ovarian cancer cell migration via a Ras-MEK kinase 1 pathway. Cancer Res 2004; 64: 4209-4217.

5. Li H, Ye X, Mahanivong C, Bian D, Chun J, Huang S. Signaling mechanisms responsible for lysophosphatidic acid-induced urokinase plasminogen activator expression in ovarian cancer cells. J Biol Chem 2005; 280: 10564-10571.

6. Symowicz J, Adley BP, Woo MM, Auersperg N, Hudson LG, Stack MS. Cyclooxygenase-2 functions as a downstream mediator of lysophosphatidic acid to promote aggressive behavior in ovarian carcinoma cells. Cancer Res 2005; 65: 2234-2242.

7. Fang X, Yu S, Bast RC, Liu S, Xu HJ, Hu SX, LaPushin $R$, Claret FX, Aggarwal BB, Lu Y, et al. Mechanisms for lysophosphatidic acid-induced cytokine production in ovarian cancer cells. J Biol Chem 2004; 279: 96539661.
8. Lee Z, Swaby RF, Liang Y, Yu S, Liu S, Lu KH, Bast RC $J r$, Mills GB, Fang $X$. Lysophosphatidic acid is a major regulator of growth-regulated oncogene alpha in ovarian cancer. Cancer Res 2006; 66: 2740-2748.

9. Im DS, Heise CE, Harding MA, George SR, O'Dowd BF, Theodorescu D, Lynch KR. Molecular cloning and characterization of a lysophosphatidic acid receptor, Edg-7, expressed in prostate. Mol Pharmacol 2000; 57: 753-759.

10. Tsujino M, Fujii M, Okabe K, Mori T, Fukushima $N$, Tsujiuchi T. Differential expressions and DNA methylation patterns of lysophosphatidic acid receptor genes in human colon cancer cells. Virchows Arch 2010; 457: 669-676.

11. Pennington KP, Wickramanayake A, Norquist BM, Pennil CC, Garcia RL, Agnew KJ, Taniguchi T, Welcsh $P$, Swisher EM. 53BP1 expression in sporadic and inherited ovarian carcinoma: Relationship to genetic status and clinical outcomes. Gynecol Oncol 2013; 128: 493-499.

12. Moolenaar WH, van Meeteren $L A$, Giepmans $B N$. The ins and outs of lysophosphatidic acid signaling. Bioessays 2004; 26: 870-881.

13. Park SY, Jeong KJ, Panupinthu N, Yu S, Lee J, Han JW, Kim JM, Lee JS, Kang J, Park GG, et al. Lysophosphatidic acid augments human hepatocellular carcinoma cell invasion through LPA1 receptor and MMP-9 expression. Oncogene 2011; 30: 1351-1359.

14. Komachi M, Tomura H, Malchinkhuu E, Tobo M, Mogi C, Yamada $T$, Kimura $T$, Kuwabara $A$, Ohta $H, I m D S$, et al. LPA1 receptors mediate stimulation, whereas LPA2 receptors mediate inhibition, of migration of pancreatic cancer cells in response to lysophosphatidic acid and malignant ascites. Carcinogenesis 2009; 30: 457-465. 